\title{
Large Dimension and Low-Cost Fe-SMA Rods
}

\author{
Hande Ozcan ${ }^{1}$, Ji $\mathrm{Ma}^{2}$, Jeremy E. Schaffer ${ }^{3}$, and Ibrahim Karaman ${ }^{2, *}$ \\ ${ }^{1}$ Department of Mechanical Engineering, Texas A\&M University, College Station, TX \\ ${ }^{2}$ Department of Materials Science \& Engineering, Texas A\&M University, College Station, TX \\ ${ }^{3}$ Fort Wayne Metals Research Products Corporation, Fort Wayne
}

\begin{abstract}
The effects on sample size on abnormal grain growth in inexpensive FeMnAlNi shape memory alloy (SMAs) wires and rod were investigated. It was shown that repeated heat treatments between single phase (bcc) and two phase (bcc $+\mathrm{fcc}$ ) region resulted in abnormal grains with bamboo structure both in small sized wires and large diameter rods. Microstructural features were investigated using electron backscatter diffraction (EBSD) and it was found that $0.5 \mathrm{~mm}$ wires possess strong [011] texture whereas, large diameter rods have random texture after grain growth heat treatments.
\end{abstract}

\section{Introduction}

Shape memory materials with superelastic properties can recover large deformations triggered by changes in stress. Since the loading and unloading paths do not coincide, a hysteresis loop occurs, which signifies energy dissipation. Due to these unique properties, superelastic SMA materials have been considered for a wide range of civil engineering applications, such as bracing systems [1, 2], connectors [3], and concreate reinforcement [4-6]. As a result, the damage sustained by the structure from adverse events has been decreased and crack propagation has been prevented. Current candidate for such applications is a very well-known NiTi-based alloy called 'Nitinol'. However, NiTi alloys are expensive, are difficult to process and weld at large scales, have a limited range of operating temperatures and limited fatigue resistance [7-9]. Also, since NiTi SMAs have mainly been used in medical applications, there is an overall lack of supply in SMAs in large sizes and volumes. Recently discovered, inexpensive FeSMAs [10-14] have shown superelasticity and energy dissipation similar to NiTi but with good workability and a cost/weldability on par with advanced high strength steels. Additionally, Fe-SMAs possess an interesting meta-magnetic response where significant changes in magnetic properties occur during superelasticity.

The properties of the Fe-SMAs are sensitive to part size in that the grain size of the material, which can be grown to several inches, should exceed the smallest dimension of the part. In order to obtain large grain sizes through abnormal grain growth in FeMnAlNi SMAs, samples have been heat treated repeatedly between the single phase and two phase region in the phase diagram. Using this technique, several attempts have been made to grow abnormal grains in wires and sheets [13, 14]. However, the maximum grain size in large diameter rods, and thus maximum possible dimension of the part is currently unknown. Therefore, in the present work, the grain growth in FeMnAlNi alloys with variable wires and rod diameters was studied.

\section{Methods}

Ingots with a nominal composition of Fe-34Mn-15Al$7.5 \mathrm{Ni}$ (at.\%) were prepared by vacuum induction melting. Cast ingots were hot extruded to $2 \mathrm{~mm}$ and 4.6 $\mathrm{mm}$ diameter rods. Wire production was performed as follows; cast rods were first hot extruded at $1000{ }^{\circ} \mathrm{C}$ followed by annealing at $1200{ }^{\circ} \mathrm{C}$ for $60 \mathrm{~min}$. Afterwards, rods were heat treated in the two phase region $\left(900{ }^{\circ} \mathrm{C}\right.$ for $\left.30 \mathrm{~min}\right)$ in an inert argon atmosphere prior to wire drawing. Finally, $0.5 \mathrm{~mm}$ wires were drawn with a $75 \%$ cold work. Cyclic heat treatments were performed in Fe-Mn-Al-Ni alloy rods and wires to promote abnormal grain growth (AGG). Fe-Mn-Al-Ni alloy specimens were encapsulated in quartz tubes and filled with high purity argon. Afterwards, cyclic heat treatments were performed as shown in Figure 1. In cyclic heat treatments, specimens were heated up to $1200{ }^{\circ} \mathrm{C}$ for $30 \mathrm{~min}$ and then cooled down to the two phase (bcc matrix + fcc precipitate) region as shown in Figure 1. This heat treatment cycle was repeated for both wires and rod specimens for 5 times. Finally, specimens were solution heat treated at $1300{ }^{\circ} \mathrm{C}$ for $30 \mathrm{~min}$ and quenched in water.

Microstructural features of the specimens were investigated using optical microscopy (OM) and crystallographic orientation of the specimens were measured using electron backscatter diffraction (EBSD) technique. OM and EBSD specimens were prepared by mechanical grinding and final polishing using $0.04 \mu \mathrm{m}$ colloidal silica. Composition of the specimens were measured using wavelength dispersive spectroscopy (WDS).

* Corresponding author: ikaraman@tamu.edu 


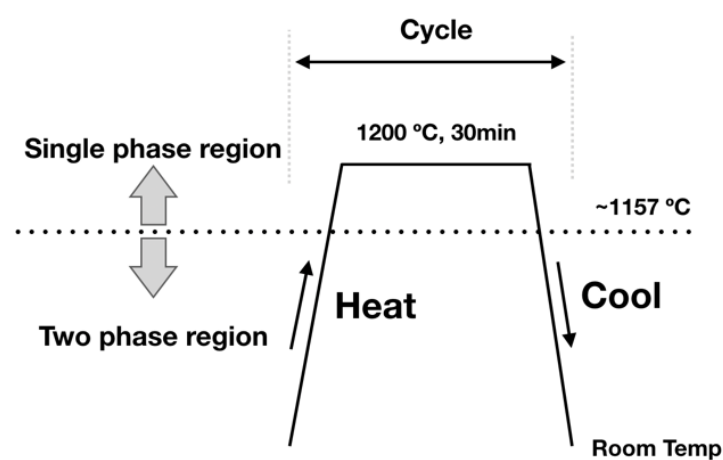

Fig. 1. Thermal cycling process for grain growth in Fe-34Mn15Al-7.5Ni (at. \%) alloy. Cycling between single phase and two-phase region promotes grain growth.

\section{Results and discussion}

Final grain sizes in the $0.5 \mathrm{~mm}$ diameter Fe-Mn-Al-Ni alloy subjected to AGG heat treatment are shown in Figure 2. A small number of grain boundaries and triple junctions are observed in the microstructure. Grain boundaries are perpendicular to the wire axis indicating that the wire has bamboo structured grains. In FeMnAlNi alloys, the grain size to diameter ratio (d/D) is an important parameter and has to be larger than 1 in order to obtain recoverable superelasticity [13]. Our results show that the $d / D$ ratio of the $0.5 \mathrm{~mm}$ wires is $\sim 8$ and therefore satisfies the conditions for superelasticity.

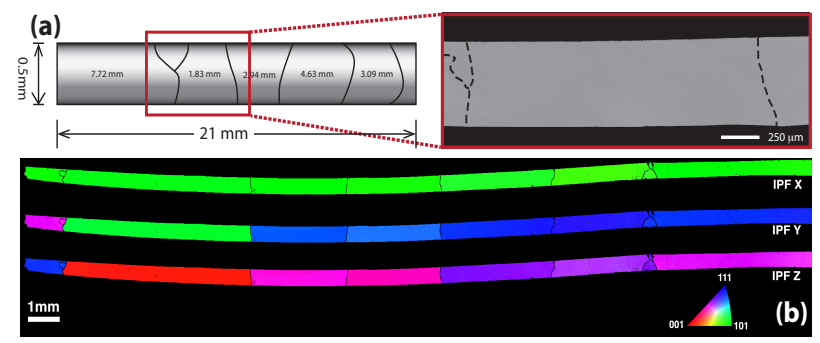

Fig. 2. a) OM image (indicated by red rectangle) and a sketch of the microstructure of a $0.5 \mathrm{~mm}$ diameter Fe-Mn-Al-Ni SMA wire. b) EBSD orientation map of the Fe-Mn-Al-Ni alloy wire. The colors represent the crystal directions parallel to the drawing direction (IPFX), transverse direction (IPFY), and the normal direction (IPFZ) given in the stereographic triangle.

Orientation map analysis of the austenite matrix in Figure $2 \mathrm{~b}$ indicates that the $0.5 \mathrm{~mm}$ diameter wire has a strong [011] texture in the drawing direction. According to the theoretical calculations on the orientation effect on superelasticity [17] FeMnAlNi alloys with [011] direction are expected to transform $10 \%$. This has also been shown experimentally in our previous work where [011] textured wires transformed $6.7 \%$ when aged at $200^{\circ} \mathrm{C}$ for $24 \mathrm{~h}$ [18].

The $2 \mathrm{~mm}$ diameter sample wire that was subjected to abnormal grain growth followed by solution heat treatment at $1300^{\circ} \mathrm{C}$ is shown in Figure 3. Grain boundaries are visible as indicated with arrows as shown in Figure 3a. Figure $3 \mathrm{~b}$ presents the EBSD orientation map in the drawing direction (IPFX) and the phase map where yellow and blue colors indicates the FCC martensite and BCC austenite respectively. Similar to the $0.5 \mathrm{~mm}$ wire, the microstructure contains very few grain boundaries and triple junctions. Grain boundaries are perpendicular to the wire axis and span across the wire diameter. The $d / D$ ratio for this case is measured around 9. Unlike the $0.5 \mathrm{~mm}$ wire, the microstructure of the 2 $\mathrm{mm}$ diameter wires contains quench in martensite after solution heat treatment as shown in the phase map. In addition, the orientation of the grains in the drawing direction (IPFX) start to vary from the [011] direction and grain orientations close to the [111] direction are observed. It is known that the orientation of the crystals effects the superelastic response [17] therefore, superelastic properties of the $2 \mathrm{~mm}$ diameter wires are expected to differ from highly textured $0.5 \mathrm{~mm}$ wires.

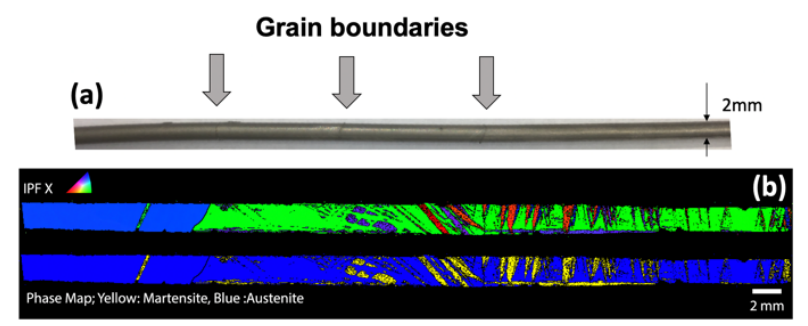

Fig. 3. a) Digital image of the $2 \mathrm{~mm}$ diameter Fe-Mn-Al-Ni alloy bar with a bamboo structure. b) EBSD orientation mapping of $2 \mathrm{~mm}$ Fe-Mn-Al-Ni alloy after AGG. The colors represent the crystal directions parallel to the drawing direction (IPFX) given in the stereographic triangle. Phase map showing the phases present in the microstructure after solution heat treatment. Yellow and blue colors represent martensite and austenite phases respectively.

Abnormal grains were obtained in the $4.6 \mathrm{~mm}$ diameter rod as shown in Figure 4. Grain boundaries are indicated with a white dotted line in optical microscopy images in Figure $4 a$ and $b$. Similar to the wires, large bamboo structured grains are frequently observed in the large diameter rods. On the other hand, small sized grains are found in the microstructure, however their number density is low. EBSD orientation mapping in the drawing direction (Figure 4c) indicates that the microstructure contains large amount of quench in martensite plates after solution heat treatment. Compositional differences caused by different thermomechanical history between wires and rod can be one possible reason for this increase in quench in martensite volume fraction.

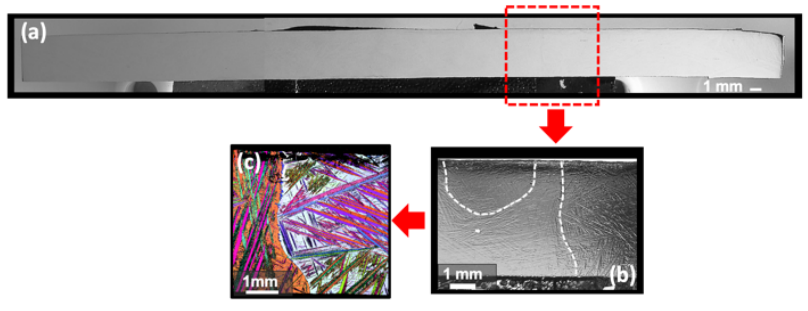

Fig. 4. a) OM image of $4.6 \mathrm{~mm}$ diameter Fe-Mn-Al-Ni SMA bar. After AGG, grain boundaries span along the wire diameter as shown in the small Figure 4bc) EBSD orientation mapping of the boundary. The colors represent the crystal directions parallel to extrusion direction (IPFX) given in the stereographic triangle. 
Grains with different crystallographic orientations are observed in large sized rods after abnormal grain growth heat treatments as shown in EBSD maps in Figure 4. Unlike small diameter wires, strong texture was not present, and texture was random. This is expected because the wire drawing process usually results in strong fibre texture in alloys [19].

The authors would like to acknowledge the financial support from the Transportation Consortium of South-Central States through a grant from the U.S. Department of Transportation/University Transportation Center Program (Grant No. 69A3551747106).

\section{Conclusions}

The major findings can be summarized as follows:

- Repeated cyclic heat treatments between single phase (bcc austenite) and two phase (bcc austenite + fcc precipitate) result in coarse bamboo grains in both small diameter wires and large diameter rods in FeMnAlNi alloys. After heat treatments, triple junctions are reduced, and grain boundaries are perpendicular to wire axis.

- After solution heat treatments from $1300^{\circ} \mathrm{C}$, quench in martensite volume fraction increases as the specimen size increases. This is attributed the compositional variations due to different thermomechanical history of the specimens.

- Cyclic abnormal grain growth heat treatments results in strong [011] texture in the drawing direction in $0.5 \mathrm{~mm}$ wires, whereas, texture become random as the sample size increases

\section{References}

1. Torra, V., Isalgue, A., Martorell, F., Terriault, P., and Lovey, F.C. (2007). Built in dampers for family homes via SMA: An ANSYS computation scheme based on mesoscopic and microscopic experimental analyses. Engineering Structures, 29(8), 1889-1902.

2. Ozbulut, O.E., Hurlebaus, S. (2010). Evaluation of the performance of a sliding-type base isolation system with a NiTi shape memory alloy device considering temperature effects. Engineering Structures, 32, 238-249.

3. DesRoches, R., Taftali, B., Ellingwood, B.R. (2010). Seismic performance assessment of steel frames with shape memory alloy connections, Part I - Analysis and seismic demands. Journal of Earthquake Engineering, 14, 471-486.

4. Saiidi, M., O’Brien, M., Sadrossadat-Zadeh, M. (2010). Cyclic response of concrete bridge columns using superelastic nitinol and bendable concrete. ACI Structural Journal, 106, 69-77.

5. Saiidi, M.S., Wang, H. (2006). Exploratory study of seismic response of concrete columns with shape memory alloys reinforcement. ACI structural journal, 103(3).

6. Saiidi, M.S., Sadrossadat-Zadeh, M., Ayoub, C., and Itani, A. (2007). Pilot study of behavior of concrete beams reinforced with shape memory alloys. Journal of Materials in Civil Engineering, 19(6), 454-461.

7. Janke, L., Czaderski, C., Motavalli, M., Ruth, J. (2005). Applications of shape memory alloys in civil engineering structures Overview, limits and new ideas. Materials \& Structures; 38: 578.

8. Song, G., Ma, N., and Li, H.N. (2006). Applications of shape memory alloys in civil structures. Engineering Structures; 28, 1266.

9. Chang, W.S., and Araki, Y. (2016). Use of shape memory alloys in construction: a critical review. In Proceedings of the Institution of Civil Engineers Civil Engineering; 169: 8795. Thomas Telford Ltd.

10. Tanaka, Y., Himuro, Y., Kainuma, R., Sutou, Y., Omor, T., and Ishida, K. (2010). Ferrous polycrystalline shape memory alloy showing huge superelasticity. Science; 327: 1488.

11. Ma, J., Karaman, I. (2010). Expanding the repertoire of shape memory alloys. Science; 327: 1468.

12. Omori, T., Ando, K., Okano, M., Xu, X., Tanaka, Y., Ohnuma, I., Kainuma, R., Ishida, K. (2011). Superelastic Effect in Polycrystalline Ferrous Alloys. Science; 333: 6871.

13. Tseng, L.W., Ma, J., Wang, S.J., Karaman, I., Kaya, M., Luo, Z.P., Chumlyakov, Y.I. (2015). Superelastic response of a single crystalline FeMnAlNi shape memory alloy under tension and compression. Acta Materialia; 89: 374-383.

14. Tseng, L.W., Ma, J., Hornbuckle, B.C., Karaman, I., Thompson, G.B., Luo, Z.P., and Chumlyakov, Y.I. (2015). The effect of precipitates on the superelastic response of [100] oriented FeMnAlNi single crystals under compression. Acta Materialia; 97: 234-244.

15. Omori, T., Okano, M., and Kainuma, R. (2013) Effect of grain size on superelasticity in Fe-MnAl-Ni shape memory alloy wire. APL Materials, 1(3), 032103.

16. Omori, T., Iwaizako, H., and Kainuma, R. (2016) Abnormal grain growth induced by cyclic heat treatment in Fe-Mn-Al-Ni superelastic alloy. Materials \& Design, 101, 263-269.

17. Tseng, L.W., Ma, J., Wang, S., Karaman, I., and Chumlyakov, Y.I. (2016). Effects of crystallographic orientation on the superelastic response of FeMnAlNi single crystals, Scr. Mater. 116, 147-151

18. Ozcan H., Ma. J., Wang, S.J., Karaman, I. Chumlyakov Y., Brown J., and Noebe R.D. (2017). Effects of cyclic heat treatment and aging on superelasticity in oligocrystalline FeMn-Al-Ni shape memory alloy wires. Scripta Materialia, 134, 66-70. 
19. Humphreys, F.J., Hatherly, M. (2004) Recrystallization and related annealing phenomena (second edition), Elsevier, 2004. 